\title{
Detrimental effects of noise on anaesthetists
}

V.S.S.N. Murthy MD, S.K. Malhotra MD,

I. Bala MD, M. Raghunathan MSc PhD*

To study the detrimental effects of operating room noise, noise levels in operating rooms were first measured and the average noise level was calculated in Decibels, which was $77.32 d B(A)$. An audiocassette of 90 min duration was prepared recording the operating room noise. The same audiocassette was used later to expose the 20 anaesthesia residents to the operating room noise in the acoustically treated rooms of audiology department. The noise level during exposure was maintained at $77.32 d B(A)$. Two cognitive functions, mental efficiency and short-lerm memory were studied. The tests used were the Trail Making Test and Digit Symbol Test for mental efficiency and the Benton Visual Retention Test for short-term memory. The mean pre-exposure scores for the Trail Making Test, Digit Symbol Test and Benton Visual Retention Test were $22.9 \pm 1.94$, $83 \pm 2.62$ and $9.55 \pm 0.51$ respectively. The mean duringexposure scores were $16.35 \pm 1.39,74.05 \pm 3.46$ and $5.8 \pm$ 0.41 respectively $(P<0.05)$. In conclusion, we observed that operating room noise reduced the mental efficiency and shortterm memory of anaesthesia residents.

Pour étudier en salle d'opération ses effets nocifs, le niveau du bruit a été établi à une valeur moyenne de $77,32 \mathrm{~dB}(A)$ calculée en décibels. Les bruits de la salle d'opération ont ensuite été enregistré apendant $90 \mathrm{~min}$ sur audiocassette. Grâce à celle-ci, on a pu exposer 20 résidents en anesthésie aux bruits de la salle d'opération dans la salle acoustique du département d'audiologie. Pendant cette expérience, le niveau de bruit a été maintenu à 77,32 $d B(A)$. Deux fonctions cognitives, l'efficience mentale et la mémoire à court terme ont été étudiées. L'efficience mentale a été évaluée avec le test du tracé à la main et le test des symboles numériques, et la mémoire à court

\section{Key words \\ HEARING: noise; \\ OPERATING ROOMS: noise; \\ MEASUREMENT TECHNIQUES: cognition, noise; MEMORY.}

From the Departments of Anaesthesia and Otolaryngology,* Post Graduate Institute of Medical Education and Research, Chandigarh, India.

Address correspondence to: Dr. S.K. Malhotra, Additional

Professor, Department of Anaesthesia, PGIMER, Chandigarh - 160012 , India.

Accepted for publication 19th March, 1995. terme, avec le test de rétention visuelle de Benton. Avant l'exposition au bruit, les scores moyens pour le test du tracé, pour le test des symboles numériques et pour le test de rétention visuelle de Benton étaient respectivement de 22,9 $\pm 1,94$, de $83 \pm 2,62$, et de 9,55 $\pm 0,51$. Durant l'exposition au bruit, la moyenne des scores se situait à 16,35 $\pm 1,39$, à $74,05 \pm$ 3,46 et à 5,80 $\pm 0,41$ respectivement $(P<0,05)$. En conclusion, nous avons observé que le bruit de la salle d'opération diminuait l'efficience mentale et la mémoire à court terme des résidents en anesthésie.

Noise is often defined as unwanted sound. ${ }^{1}$ Perhaps a better definition of noise would be the "wrong sound in the wrong place at a wrong time." ${ }^{2}$ Noise causes annoyance and a decrease in efficiency. ${ }^{3}$ The effects of noise on performance depend on the type of noise and on the task being performed. ${ }^{4,5}$ Noise levels similar to those found in operating rooms detrimentally affect short-term memory ${ }^{5}$ and cause distractions during critical periods. ${ }^{6}$ Difficult tasks that require high levels of perception processing or information processing are adversely affected by noise. ${ }^{7}$ Operating room noise is intense enough to provoke peripheral vasoconstriction, dilatation of the pupil, and other subtle physiological effects, as well as interfere with speech communication and thereby provoke irritation. ${ }^{8}$ The present study was designed to correlate functional impairment and operating room noise.

\section{Methods}

As a first step, a preliminary survey of noise levels was undertaken in all the operating rooms, situated in the operating theatre complex of our institute. Each operating room was designated for a different surgical specialty. The noise measuring instrument used was the Precision Integrating Sound Level Meter, Bruel \& Kjaer Type 2230. During the measurements, the instrument was positioned on the anaesthesia machine (about $25 \mathrm{~cm}$ from the anaesthetist) in such a way that its microphone was at the same level as the anaesthetist's ear so that the measured noise levels were similar to those heard by the anaesthetist. Decibel measurements were made on " $A$ " scale, $\mathrm{dB}(\mathrm{A})$, the scale most commonly used in noise surveys. The " $A$ " scale closely correlates with noise nuisance and hazard assessment for human beings. ${ }^{9}$ The noise levels were measured for $15 \mathrm{~min}$, during the preparation period 
TABLE I Noise levels in operating rooms (dB(A))

\begin{tabular}{|c|c|c|c|c|c|c|c|c|c|c|c|c|c|c|c|}
\hline & \multicolumn{3}{|c|}{ Ortho } & \multicolumn{3}{|c|}{ General Surgery } & \multicolumn{3}{|c|}{ Cardio } & \multicolumn{3}{|c|}{ Emergency } & \multicolumn{3}{|c|}{ Neuro } \\
\hline & 1 & 2 & 3 & 1 & 2 & 3 & 1 & 2 & 3 & 1 & 2 & 3 & $l$ & 2 & 3 \\
\hline $\mathbf{L}_{\min }$ & 76 & 74 & 75 & 76 & 72 & 74 & 76 & 68 & 74 & 78 & 74 & 76 & 74 & 68 & 72 \\
\hline $\mathrm{L}_{\max }$ & 98 & 88 & 87.5 & 88.5 & 78.5 & 86 & 99 & 86 & 98.2 & 95 & 93 & 96 & 96.5 & 98 & 99.2 \\
\hline $\mathrm{L}_{\mathrm{eq}}$ & 79.2 & 76 & 77.5 & 78 & 74.6 & 76.8 & 78.2 & 69 & 76.8 & 79.5 & 77.2 & 78 & 82.5 & 78.2 & 81.2 \\
\hline
\end{tabular}

1. First test period.

2. Second test period.

3. Third test period.

in each of the operating rooms. The noise indices recorded were $\mathrm{L}_{\min }$ (the lowest level), $\mathrm{L}_{\max }$ (the highest level), $L_{e q}$ (continuous equivalent sound level or average over a given period). According to preliminary survey, high noise level operating rooms were Orthopaedics Surgery (OPS), General Surgery (GS), Cardiothoracic Surgery (CTS), Emergency Operation Theatre (EOT) and Neurosurgery (NS). These operation theatres were studied more in detail. The instrument used, the position of the microphone during measurement, and the noise indices recorded were the same as in the preliminary survey. In each operating room, noise levels during a complete operation were measured. The noise levels were measured over three to five hours which was divided into three test periods.

The first included the period of preparation and induction, the second included surgery, and the third included reversal of the relaxant and extubation of the trachea. At the end of each test period $L_{\min }, L_{\max }$ and $L_{e q}$ values of that period were noted as shown by the sound level meter. After measuring noise levels individually in each of the rooms, the average noise level was calculated as the arithmetic mean of $\mathrm{L}_{\mathrm{eq}}$ values of all test periods in all five operation theatres.

A 90 min audiocassette (TDK acoustic cassette Type I) was prepared recording the operating room noise, which included the noise made by surgical instruments, suction apparatus, monitors and alarms, the ambient noises of nurses and other operating room personnel. The recording was made with a professional stereocassette recording system (Ahuja). The microphones were placed $25 \mathrm{~cm}$ from the anaesthetist. The same audio cassette was used later to expose the residents to the pre-recorded operating room noise, so that exposure was uniform and the results obtained could be compared.

After approval by the hospital ethics committee and informed consent 20 anaesthesia residents were studied. Their mean age was $27.7 \mathrm{yr} \pm 2.03$ (SD); 15 were male and five female. Those with any hearing defect or psychiatric disorder or receiving any psychopharmocological treatment were excluded from the study. The cognitive function tests studied were the Trail Making Test ${ }^{10}$ (TMT) and Digit Symbol Test " (DST) for mental efficiency. Short-term memory was tested using the Benton Visual Retention Test ${ }^{12}$ (BVRT).

Residents acted as their own controls. The study was conducted in two settings, pre-exposure and duringexposure to noise. All tests were conducted in the acoustically treated rooms of the Audiology Department of our institute. In order to avoid a "practice effect" on cognitive functions, a gap of one week was kept between the two settings.

During the study, the resident sat comfortably in a chair in the centre of the exposure room with loud speakers fitted to the walls. A tape recorder and amplifier were placed in an adjacent control room. Pre-exposure tests (without noise) were studied first. The sequence of administration of tests was TMT, DST, BVRT. After one week, the same tests were repeated in the same order, and the recorded operating room noise was played through loud speakers. All tests were carried out ten minutes after the beginning of exposure. Both the preexposure and during-exposure tests were conducted by the same investigator. The noise level in the exposure room was monitored at the ear level approximately 25 $\mathrm{cm}$ from the subject's head, with the help of sound level meter (Bruel \& Kjaer type 2230) and was maintained at the same level as that of the calculated average operating room noise (77.32 $\mathrm{dB}(\mathrm{A}))$, throughout the exposure period.

The results were tabulated and compared using paired student $t$ test. A $P$ value of $<0.05$ was considered to be statistically significant.

\section{Results}

The average noise level $\mathrm{L}_{\text {eq }}, 77.32 \mathrm{~dB}(\mathrm{~A})$, was taken as the average noise level in our operation theatres (Table I). Mental efficiency and short-term memory were reduced by exposure to noise (Table II). The mean preexposure scores for TMT, DST and BVRT were 22.9 (SD1.94), 83 (2.62) and 9.55 (0.51) respectively. The mean during exposures scores were 16.35 (1.39), 74.05. (3.46) 
TABLE II Effect of noise on cognitive function test scores (mean \pm SD)

\begin{tabular}{llrl}
\hline Score & Test & \multicolumn{1}{c}{$\begin{array}{l}\text { Pre- } \\
\text { exposure }\end{array}$} & $\begin{array}{l}\text { During } \\
\text { exposure }\end{array}$ \\
\hline 1 & $\begin{array}{l}\text { Mental efficiency } \\
\text { Trail making test }\end{array}$ & $22.9 \pm 1.94$ & $16.35^{*} \pm 1.39$ \\
& $\begin{array}{l}\text { Digit symbol test } \\
23 \pm 2.62\end{array}$ & $74.05^{*} \pm 3.46$ \\
& $\begin{array}{l}\text { Short-term memory } \\
\text { Benton visual retention test }\end{array}$ & $9.55 \pm 0.51$ & $5.8^{*} \pm 0.41$ \\
\hline
\end{tabular}

$* P<0.05$.

and $5.8(0.41)$ respectively. The deterioration in the scores was statistically significant for all tests $(P<0.05)$.

\section{Discussion}

In all operating rooms, noise levels were highest during the first test period, than in the second and third test periods, implying that noise levels were high during the preparation period of the operation. Hodge and Thompson' ${ }^{9}$ observed that the noisiest time was usually during the preparation period of the operation and Davies et al. ${ }^{13}$ found that the preparation period was noisier than at induction, but the education period was found to be most noisy.

During exposure to pre-recorded operating room noise, residents showed deterioration in the tests for mental efficiency and short-term memory. There is no similar study involving operating room noise and operating room personnel. Data from experiments in industry and laboratory studies ${ }^{4}$ show that if the average rate of work is of concern, noise is relatively unimportant. If, however, accidents or errors caused by momentary inefficiency are a serious risk, then noise increases the hazard and should be reduced. In a study of workers in a textile mill the efficiency of weavers are examined when they wore ear plugs on alternate weeks for six months. The efficiency of the workers was about $12 \%$ greater when wearing the ear plugs. Ear plugs reduced the noise exposure and improved efficiency. ${ }^{14}$ Noise levels similar to those found in operating rooms detrimentally affect short-term memory. ${ }^{5}$ In our study there was a deterioration in memory due to exposure to noise as shown by BVRT test $(P<$ 0.05).

On the other-hand, several studies have shown a beneficial effect of music. Wolf and Weiner ${ }^{15}$ have suggested that the presence of familiar background noise may improve vigilance. Subsequent studies ${ }^{16,17}$ have substantiated the beneficial effects of background music on monitoring performance.

The present study may be criticised because it was not performed in the work situation. Instead, it was car- ried out in acoustically treated rooms of the Audiology Department outside the operating room. There are two reasons for this. Firstly, the major weakness of industrial studies is lack of control of other conditions besides the noise which is being investigated. ${ }^{4}$ This study avoided influence of stress factors other than noise thereby studying the effect of noise exclusively. Secondly, we avoided the distraction from patient monitoring which would have become unavoidable had the tests been conducted in an operating room. This sacrifices realism, but this is the price of a controlled study.

Much of the anaesthetist's job involves obtaining information from various sources, verifying the validity of the information, formulating priorities, and taking prompt and immediate action based on the information obtained. ${ }^{18}$ Administration of anaesthesia is a task where even momentary inefficiency can result in serious consequences to the patient. Hence operating room noise should be reduced.

In conclusion, exposure to noise levels similar to those found in our operating rooms caused deterioration in mental efficiency and short-term memory in anaesthesia residents.

\section{Acknowledgements}

We acknowledge the cooperation of the residents of the anaesthesia department but for whose active participation it would not have been possible to complete the study.

\section{References}

1 Harris CM. Introduction. In: Harris CM (Ed.). Handbook of Noise Control, 2nd ed. New York: McGraw-Hill, 1979; 1: $1-15$.

2 Park JE. Environment and health. In: Park JE, Park K (Eds.). Text Book of Preventive and Social Medicine, 12th ed. Jabalpur: M/S Banarsidas Bhanot Publishers, 1989: 378-9.

3 Molino JA. Annoyance and noise. In: Harris CM (Ed.). Handbook of Noise Control, 2nd ed. New York: McGrawHill, 1979: 16.1-16.9.

4 Broadbent $D$. Human performance and noise. In: Harris CM (Ed.). Handbook of Noise Control, 2nd ed. New York: McGraw-Hill, 1979: 15.1-15.23.

5 Hockey GRJ. Effects of noise on human work efficiency. In: May D (Ed.). Handbook of Noise Assessment. New York: Van Nostrand Reinhold, 1978: 335-72.

6 Poulton $E$. A new look at the effects of noise: a rejoinder. Psychol Bull 1978; 85: 1068-79.

7 Eschenbrenner $A J J r$. Effects of intermittent noise on the performance of a complex psychomotor task. Hum Factors 1971; 13: 59-63.

8 Shapiro RA, Berland T. Noise in the operating room. N Engl J Med 1972; 287: 1236-8. 
9 Hodge B. Thompson JF. Noise pollution in the operating theatre. Lancet 1990; 335: 891-4.

10 Reitan RM. Validity of the trail making test as an indication of organic brain damage. Percept Mot Skills 1958; 8: 271-6.

11 Wechsler D. Wechsler Adult Intelligence Scale. New York: The Psychological Corporation, 1955.

12 Benton $A L$. The Revised Visual Retention Test, 3rd ed. New York: The Psychological Corporation, 1963.

13 Davies JM, Ewen A, Cuppage A, Gilbert D, Winkelaar $R$. Noise levels in the operating room - a comparison of Canada and England. Anaesth Intensive Care 1989; 17: 98-9.

14 Weston HC, Adams S. Part III, Report 65, Industrial Health Research Board, London. HM Stationary Office, 1932.

15 Wolf RH, Weiner FF. Effects of four noise conditions on arithmetic performance. Percept Mot Skills 1972; 35: 928-30.

16 Corhan CM, Gounand BR. Types of music, schedules of background stimulation, and visual vigilance performance. Percept Mot Skills 1976; 42: 662.

17 Fontaine $D W$, Schwalm ND. Effects of familiarity of music on vigilant performance. Percept Mot Skills 1979; 49: 71-4.

18 Weinger $M B$, Englund $C E$. Ergonomic and human factors affecting anesthetic vigilance and monitoring performance in operating room environment. Anesthesiology 1990; 73: 995-1021. 